\title{
Contrasting styles of oxygen isotope exchange
}

\author{
J.W. Valley \\ J.M. Eiler \\ M.J. Kohn \\ M.J. Spicuzza \\ L.P. Baumgartner \\ D. Elsenheimer \\ C.M. Graham
}

Dept. of Geology, Univ. of Wisconsin, Madison, WI 53706 USA.

Dept. of Geology, Univ. of Edinburgh, Edinburgh EH9 3JW,
Exchange of oxygen isotopes encrypts a sensitive record of the thermal evolution and fluidexchange history of igneous and metamorphic rocks. Deciphering this record requires measurement of isotope ratios at an appropriate scale together with understanding of the processes involved: diffusion, recrystallization, new mineral growth, and fluid flow.

Several techniques are now available for oxygen isotope analysis in minerals; each has unique advantages. Externally-heated $\mathrm{Ni}$ reaction vessels have precisions of \pm 0.1 to $0.3 \%$ ( $1 \sigma)$ from $10 \mathrm{mg}$ samples. Laser probe analysis is precise $\pm 0.1 \%$ for powdered samples down to $500 \mu \mathrm{g}$, and $25 \mu \mathrm{g}$ samples may soon be equally precise. Analysis of refractory minerals such as olivine, garnet, spinel, aluminosilicate, and zircon is routine, but minerals that react with $\mathrm{BrF}_{5}$ at low $\mathrm{T}$ can be a problem. In situ laser analysis produces poorer precision due to edge effects, and poorer spatial resolution. Ion microprobe analysis can attain spatial resolution of $1-10 \mu \mathrm{m}$ with precision of $\pm 1 \%$ for 45 -minute analyses of electrically conductive minerals such as magnetite and

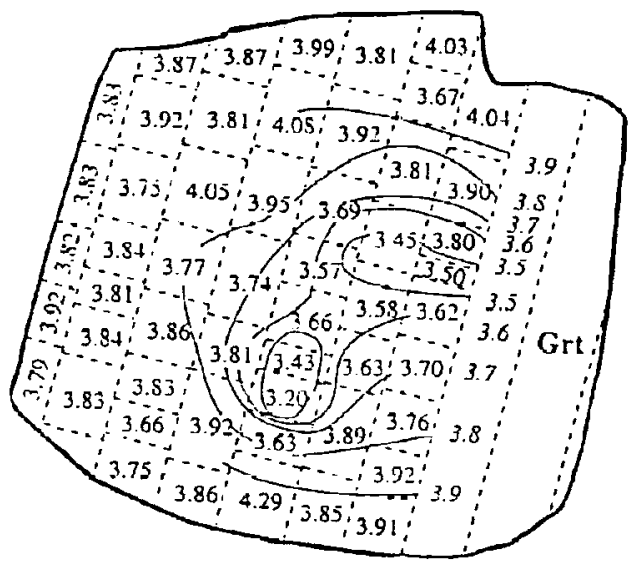

Fig. 1. Laser probe analyses of garnet. ilmenite. Precision of $\pm 0.3 \%$ has been achieved by multiple analyses of homogeneous magnetite (Eiler et al., 1994a). Analysis of insulating minerals is complicated by sample charging. Because the capabilities of ion and laser probes are developing rapidly, statements about accuracy and precision should be evaluated against tables of standard and sample data.

Refractory minerals can preserve isotopic compositions from crystallization. For example, amphibolite facies garnets (5-8mm dia.) have been contoured in $\delta^{18} \mathrm{O}$ at the $0.1 \%$ level revealing $0.5 \%$ zonation, consistent with continuous closed system growth during prograde metamorphism (Fig. 1, Kohn et al., 1993). In another study, igneous zircons in orthogneiss and detrital zircons in quartzite preserve oxygen isotope compositions through granulite facies metamorphism (Valley et al., 1994). Thus, refractory minerals such as garnet, zircon, olivine and pyroxene can be used to see through metamorphism or hydrothermal alteration. For zircon and garnet, combining $\mathrm{U}-\mathrm{Pb}$ geochronology with oxygen isotope microanalysis provides new information on timing of oxygen exchange.

Refractory minerals that equilibrate above their blocking temperatures and cool slowly are subject

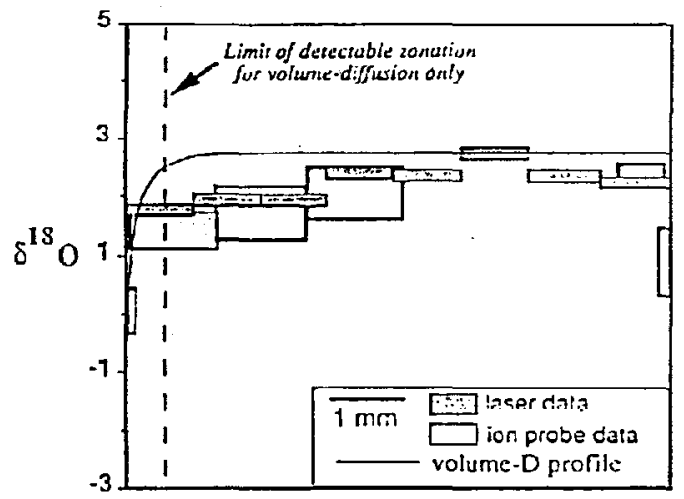

Fig. 2. Laser and ion probe analyses of magnetite. 


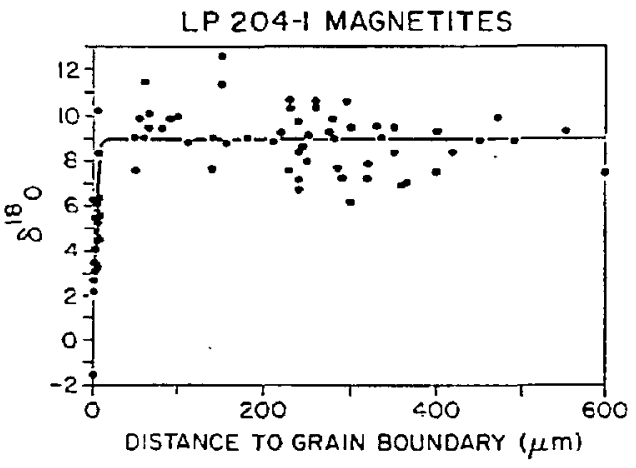

FIG. 3. Ion probe analyses of $1 \mathrm{~mm}$ magnetites.

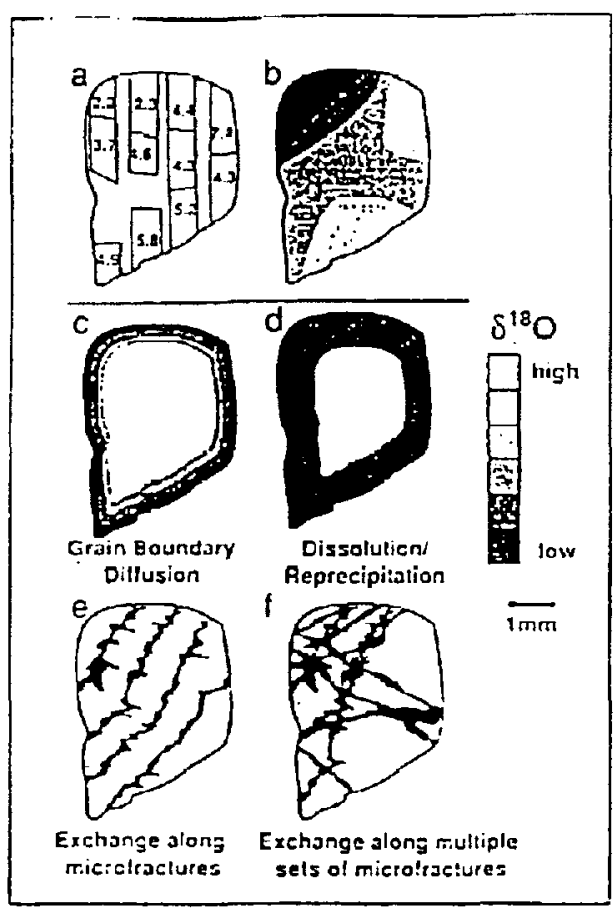

Fig. 5. Laser probe analyses of quartz.

to diffusion and exchange in open and/or closed systems. For example, magnetite in a granulite facies gneiss preserves diffusion profiles adjacent to both faster diffusing feldspar and slower diffusing garnet (Fig. 2, Eiler et al., 1994b). The size and shape of these profiles show that both volume and grain boundary diffusion need to be considered in any quantitative study. Magnetites in granulite facies marbles show contrasting intra-grain oxygen isotopic patterns indicative of different fluid exchange mechanisms. $1 \mathrm{~mm}$ magnetites in one sample contain homogeneous cores resulting from closed system cooling and exchange, and thin ${ }^{18} \mathrm{O}$

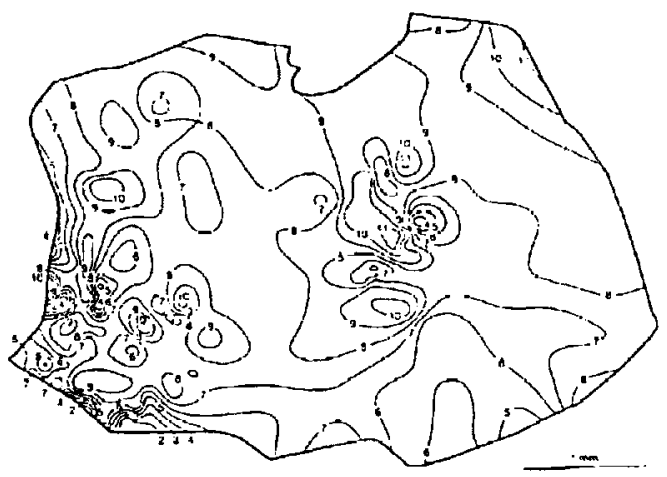

Fig. 4. Ion probe analyses of a $5 \mathrm{~mm}$ magnetite.

depleted rims reflecting open system exchange with retrograde fluid (Fig. 3, Valley and Graham, 1991). $5 \mathrm{~mm}$ magnetites in a nearby marble show apparently random and complex $9 \%$ variations (Fig. 4, Valley and Graham, 1993) that are found by ion beam etching to correlate with cryptic cracks which provided retrograde fluid exchange pathways. In another example, quartz in hydrothermally altered granite also shows seemingly random variations in $\delta^{18} \mathrm{O}$ from 2.3 to $7.4 \%$ (Fig. 5, Elsenheimer and Valley, 1993). The complexity of this pattern of exchange argues against: instantaneous equilibration, diffusive exchange inward from a grain boundary fluid, growth of a low $\delta^{18} \mathrm{O}$ rim, or exchange along a single generation of cracks. Exchange was more likely facilitated by a complex network of at least two generations of microfractures.

New microanalytical capabilities have also spurred theoretical and experimental studies of oxygen diffusion, fluid flow and grain growth. It is now clear that calculations of 1-D diffusive penetration distances or blocking temperature may be reliable in some situations, but are in error elsewhere. Fast grain boundary diffusion, modes, and variable water fugacity must be considered (Eiler et al., 1993). Instantaneous isotopic equilibration is a poor assumption in most environments. Mineral thermometers are also speedometers and fluid barometers. Oxygen isotope temperatures are frequently lower than peak temperature, but erroneously high temperatures are also possible.

In summary, new microanalytical techniques show that multiple processes, operating at different length and time scales, are often superimposed on high temperature rocks to create complex patterns of oxygen isotope zonation and disequilibrium. In well defined situations, the effects of these processes can be isolated and thermal and fluid histories deciphered. 